\title{
Adaptação para Libras da Escala Multidimensional de Satisfação de Vida para Adolescentes
}

\author{
Rosângela Prescendo Tonin ${ }^{1}$, Cláudia Cristina Fukuda \\ Universidade Católica de Brasília, Brasília-DF, Brasil
}

\section{RESUMO}

O objetivo da pesquisa foi adaptar para Libras, a Língua Brasileira de Sinais, a Escala Multidimensional de Satisfação de Vida para Adolescentes (EMSVA). A adaptação foi realizada em seis etapas: 1. adaptação semântica e tradução para Libras; 2 . síntese das versões traduzidas; 3. avaliação da síntese por juízes; 4. análise semântica da escala em Libras; 5. retrotradução e 6. análise empírica. Nas três primeiras etapas e na retrotradução, os participantes surdos e ouvintes eram adultos, proficientes em Libras e em português, com formação universitária. A análise semântica foi desenvolvida por meio de grupo focal com adolescentes surdos. Na última etapa, 50 adolescentes surdos, estudantes de escolas públicas do Distrito Federal responderam ao instrumento. A versão adaptada da EMSVA demonstrou boa consistência interna $\left(\lambda^{2}=0,89\right)$ na amostra de adolescentes surdos.

Palavras-chave: surdez; adolescência; língua de sinais; satisfação de vida.

\section{ABSTRACT - Adaptation of the Multidimensional Scale of Life Satisfaction for Adolescents to Brazilian Sign Language}

The aim of this study was to adapt the Multidimensional Life Satisfaction Scale for Adolescents (EMSVA) to Brazilian Sign Language (LIBRAS). The adaptation was carried out in six steps: 1. semantic adaptation and translation into LIBRAS; 2 . synthesis of the translated versions; 3. evaluation of the synthesis by judges; 4 . semantic analysis of the scale in LIBRAS; 5 . back translation and 6. empirical analysis. In the first three stages and in the back-translation the deaf and hearing participants were adults, proficient in LIBRAS and the Portuguese language, with university level education. Semantic analysis was developed through a focus group with deaf adolescents. In the final stage, 50 deaf adolescents, students of public schools in the Federal District answered the instrument. The adapted version of the EMSVA presented good internal consistency $\left(\lambda^{2}=0.89\right)$ in the sample of deaf adolescents.

Keywords: deafness; adolescence; sign language; life satisfaction.

\section{RESUMEN - Adaptación de la Escala Multidimensional de Satisfacción con la Vida para la Lengua Brasileña de} Señales para Adolescentes

El objetivo de la investigación fue adaptar la Escala Multidimensional de Satisfacción con la Vida para Adolescentes (EMSVA) para Libras, la Lengua Brasileña de Señales. La adaptación se realizó en seis etapas: 1. adaptación semántica y traducción para Libras; 2. síntesis de las versiones traducidas; 3. evaluación de la síntesis por jueces; 4. análisis semántico de la escala en Libras; 5. retrotraducción y 6. análisis empírico. En las primeras tres etapas y en la traducción inversa, los participantes sordos y oyentes eran adultos, especializados en libras y en portugués, con formación universitaria. El análisis semántico fue desarrollado por medio de un grupo focal con adolescentes sordos. En la última etapa, 50 adolescentes sordos, estudiantes de escuelas públicas del Distrito Federal contestaron al instrumento. La versión adaptada de EMSVA demostró buena consistencia interna $\left(\lambda^{2}=0,89\right)$ en la muestra de adolescentes sordos.

Palabras clave: sordera; adolescencia; lenguaje de señas; satisfacción con la vida.

Vários estudos deram um caráter inovador à Psicologia no início deste novo milênio. Tal fato ampliou o campo de estudo dessa área que passou a preocupar-se não apenas com aspectos voltados à dor e à infelicidade humanas (Galinha \& Ribeiro, 2005). Inicia-se assim a Psicologia Positiva que percebe a Psicologia não apenas como uma ciência subsidiária da Medicina, voltada à doença ou à saúde. Engloba também a felicidade, a introspecção, o amor e o crescimento humano (Seligman \& Csikszentmihalyi, 2000).

A partir dessa nova forma de pensar a Psicologia, surge o estudo científico de bem-estar subjetivo (BES), desenvolvido, em parte, como uma reação à ênfase dada aos estados psíquicos negativos (Myers \& Diener, 1995; Diener, Suh, Lucas, \& Smith, 1999; Galinha \& Ribeiro, 2005). A satisfação de vida é um dos elementos do BES e

${ }^{1}$ Endereço para correspondência: SRES, Quadra 04, Bloco U,Casa 32, 70648-213, Brasília-DF. Tel.: (61) 99675-4867. E-mail: rosangelaprescendo@gmail.com As autoras agradecem aos participantes adultos surdos e ouvintes pela dedicação no processo de adaptação, às três escolas da rede pública do Distrito Federal que permitiram a realização do estudo e, em especial, aos estudantes surdos dessas instituições pela valiosa contribuição. 
um preditor de resultados positivos em muitos domínios da vida. Adultos com alta satisfação de vida relatam maior sucesso profissional, interpessoal, ocupacional e melhor saúde física e mental, descrevem ainda melhores relacionamentos sociais, maior satisfação no trabalho, melhor produtividade e são mais longevos (Lewis, Huebner, Malone, \& Valois, 2011). No Brasil, Paludo e Koller (2007) e Passareli e Silva (2007) apoiam esse novo olhar voltado ao estudo das forças e potencialidades humanas. Os autores confirmam a mudança de foco nas pesquisas empíricas até então direcionadas às emoções negativas.

Durante muito tempo, os estudos sobre a avaliação da satisfação de vida se voltavam a questões relacionadas a condições socioeconômicas, empregos e salários. Fatores socioemocionas e psicológicos foram introduzidos no estudo da satisfação com a vida apenas no final do século passado (Veenhoven, 1994). Desse modo, a satisfação com a vida compreende uma avaliação cognitiva dos indivíduos sobre sua qualidade de vida global com base em seus próprios padrões (Lewis, Huebner, Malone, \& Valois, 2011). Está relacionada com as características particulares das pessoas, a rede de apoio e relações próximas, além da convivência em ambientes positivos e de envolvimento com o estudo, trabalho e lazer (Myers \& Diener, 1995). Segundo os autores, a fé também influencia a satisfação de vida, pois implica apoio social, propósito e esperança. Quanto à adolescência, fatores associados às potencialidades pessoais como estar bem com os estudos, consigo mesmo e com a vida relacionam-se a uma maior satisfação de vida (Strelhow, Bueno, \& Câmara, 2010).

Ao considerar tais aspectos relacionados à Psicologia Positiva e ao reconhecer a singularidade linguística dos surdos (Sacks, 1998), nesta pesquisa propõe-se adaptar à Língua Brasileira de Sinais (Libras) uma escala de satisfação de vida para adolescentes surdos. A proposta se sustenta na ideia do respeito e reconhecimento das diferenças para incluir, no desenvolvimento de estratégias que atendam às particularidades dessa população imersa numa cultura predominantemente ouvinte (Mantoan, 2012). No presente estudo, adota-se o modelo socioantropológico da surdez, reconhecida como uma diferença cultural e linguística (Skliar, 2013).

No Brasil, apesar dos avanços nos últimos anos em que houve conquistas para as pessoas surdas, entre elas a oficialização da língua de sinais e a disponibilização de intérpretes em algumas instituições públicas, ainda permanece um distanciamento entre o estabelecido em lei e a prática cotidiana em diversos campos sociais, entre eles, na educação (Bissoto, 2013).

Estudos demonstram que a aquisição e o uso da língua de sinais pelos surdos desempenham um papel significativo na qualidade de vida dessas pessoas. Hintemair (2008), estudou a autoestima e a satisfação de vida de surdos alemães e verificou que os dados sobre a situação de comunicação apresentaram diferenças significativas, as pessoas surdas que utilizavam sinais obtiveram maior pontuação em recursos pessoais do que aqueles sem tal competência. Quanto ao ambiente educacional, encontrou associação entre frequentar uma escola para surdos e obter maiores escores nos recursos pessoais. Pessoas surdas com melhores recursos psicológicos possuíam maior autoestima e satisfação de vida. Além disso, o autor destacou que os surdos capazes de transitar tanto na cultura dos surdos quanto na dos ouvintes tinham, em geral, condições mais favoráveis para alcançar o bem-estar psicossocial. Al-shammari et al. (2014) estudaram o ajustamento socioemocional de estudantes surdos de duas instituições de ensino privadas e inclusivas na Arábia Saudita, os estudantes relataram atitudes positivas em relação a metas pessoais, fazer amigos e bem-estar nos contextos educativos.

A partir das evidências apresentadas, é indispensável reconhecer a singularidade linguística dos surdos, considerar as características dessa população para realizar avaliações psicológicas mais efetivas (Samady, Sadler, Nakaji, \& Malcarne, 2008; Pardo-Guijarro, Woll, Moya-Martínez, Martínez-Andrés, Cortés-Ramírez, \& Martínez-Vizcaíno, 2013). Dessa forma, a maneira com melhor eficácia encontrada pelos autores para atender a esses pressupostos foi a elaboração ou adaptação para as línguas de sinais de instrumentos de medida em Psicologia.

Sobre instrumentos desenvolvidos ou adaptados para línguas de sinais tanto na literatura nacional quanto na internacional, poucos foram encontrados. Entre eles, Samady et al. (2008) fizeram a tradução da Escala Multidimensional de Lócus de Controle de Saúde (MHLC) em língua americana de sinais (ASL). Pardo-Guijarro et al. (2013) ao observarem os problemas de compreensão leitora dos surdos realizaram um estudo para testar a validade e a confiabilidade do Questionário de Qualidade de Vida Relacionado à Saúde - KIDSCREEN-27 adaptado à língua espanhola de sinais. No Brasil, Chaveiro, Duarte, Barbosa, Porto e Fleck (2013) desenvolveram um estudo para adaptar e traduzir os instrumentos WHOQOL-BREF e WHOQOL para Libras, a fim de medir a qualidade de vida dos surdos brasileiros.

Dentre os diversos instrumentos brasileiros para a aferição do nível de satisfação com a vida, destaca-se a Escala Multidimensional de Satisfação de Vida para Adolescentes (EMSVA) desenvolvida por Segabinazi, Giacomoni, Dias, Teixeira e Moraes (2010). É um instrumento direcionado ao público adolescente com bons índices de consistência interna e fortes evidências de validade de construto e concorrente. Além disso, os itens são afirmações curtas e diretas, aspectos favoráveis à tradução para Libras.

Evidências de validade de construto da EMSVA foram obtidas em uma amostra de 452 adolescentes de escolas públicas e privadas de Santa Maria (RS). A análise fatorial exploratória demonstrou a existência de sete fatores bem estruturados, todos os itens apresentaram 
cargas fatoriais superiores a 0,34 nos fatores que carregaram. A Consistência Interna (CI) dos fatores foi obtida por meio de alfa de Cronbach e variou entre 0,70 a 0,91. A CI do escore geral foi 0,93 (Segabinazi, et al., 2010). Outro estudo realizado com 420 adolescentes de Porto Alegre (RS) obteve resultado de CI para o escore geral da escala um pouco menor, de 0,87 (Silva, Giordani, \& Dell'Aglio, 2017).

Ao considerar que atualmente no Brasil foram identificados apenas dois instrumentos adaptados para Libras e a necessidade de fomentar a produção de instrumentos que possam subsidiar tanto a avaliação psicológica quanto a pesquisa com a população surda, o objetivo deste estudo foi adaptar para Libras a EMSVA para a adolescentes surdos.

\section{Método e Resultados}

A adaptação da Escala Multidimensional de Satisfação de Vida para Adolescentes - EMSVA foi realizada em seis etapas: 1. adaptação semântica e tradução para Libras; 2. síntese das versões traduzidas; 3. avaliação da síntese por juízes; 4. análise semântica da escala em Libras por um grupo focal; 5. retrotradução e 6. análise empírica. O método e resultados serão apresentados por cada etapa, separadamente. A versão da EMSVA utilizada nessa adaptação compõe-se de 52 itens, divididos em sete componentes: Família $(\alpha=0,91)$; Self $(\alpha=0,87)$; Escola $(\alpha=0,85)$; Self Comparado, $(\alpha=0,85)$; Não violência $(\alpha=0,70)$; Autoeficácia $(\alpha=71)$; Amizade $(\alpha=0,82)$. A análise da consistência interna da escala total foi de 0,93 .

\section{Etapa I - Adaptação Semântica e Tradução em Libras}

\section{Participantes}

Participaram da adaptação semântica e da tradução para Libras da EMSVA três adultos surdos e três adultos ouvintes, organizados em duplas compostas por um ouvinte e um surdo. Os participantes tinham idades entre 30 e 45 anos, eram integrados à comunidade surda e bilíngues (proficientes em Libras e português) e tinham formação de graduação ou pós-graduação.

\section{Procedimentos}

Para cada dupla foi apresentada a escala multidimensional de satisfação com a vida para adolescentes em português e lhes foi solicitado que lessem o instrumento observando a semântica dos itens em português e pensassem na melhor forma de apresentá-los em língua de sinais para os adolescentes surdos. Em um segundo encontro, depois de realizada a adaptação semântica e decididas as alterações em algumas estruturas das frases que compõem os itens da escala, foi realizada a primeira gravação do instrumento traduzido para Libras. A gravação foi feita por um participante de cada dupla, duas duplas optaram pelo participante surdo e uma pelo ouvinte.

\section{Resultados}

Durante a filmagem da primeira versão da escala adaptada para língua de sinais, os participantes tiveram especial preocupação com a expressão facial e corporal. Por exemplo, no item "Eu sou alegre", a expressão de alegria ficou bem marcada, bem como a expressividade no item "Sou irritado".

Os participantes se preocuparam em adotar um vocabulário acessível ao surdo. Dos 52 itens, 42 foram adaptados de forma bastante semelhante pelas três duplas e sem maiores problemas. Dez itens, no entanto, necessitaram de maior reflexão. Por exemplo, o item três: "Sou compreendido em casa", foi adaptado de diferentes formas por uma dupla de participantes, a saber: "Dentro de casa, minha família me apoia", "Minha família me compreende" e "Em casa, minha família me entende". Outra dupla no item 16: "Eu gostaria que meus amigos fossem diferentes", fez as seguintes adaptações: "Meus amigos podem ser os mesmos, mas precisam mudar o comportamento"; "Gostaria que meus amigos tivessem sentimentos diferentes" e "Eu quero amigos com sentimentos, atitudes e pensamentos diferentes".

No item 47, "Eu me considero uma pessoa descontraída”, por não existir um sinal em Libras para o termo descontraído, houve a necessidade de usar classificadores. Classificadores são uma representação de Libras, usados no caso de não haver o sinal próprio para determinada palavra ou para mostrar detalhes específicos, possibilitando a descrição de pessoas, animais e objetos, bem como sua movimentação ou localização (Brito, 1995).

Dessa forma, após discussão e consenso sobre qual forma de adaptação mantinha maior equivalência com o instrumento original, bem como tinha um vocabulário mais adequado para os adolescentes surdos, cada dupla elegeu uma única versão para os 10 itens que geraram maior dificuldade na adaptação. Além disso, os tradutores sugeriram associar os níveis da escala de respostas a imagens (smiles), para facilitar a compreensão ao responder cada item e aumentar a aproximação com a linguagem de sinais.

\section{Etapa II -Síntese das Versões Traduzidas}

\section{Participantes}

Participaram da síntese das três versões da escala traduzida um adulto surdo e um ouvinte, ambos com formação universitária em Letras/Libras e bilíngues (Português/Libras).

\section{Procedimentos}

Com as adaptações sinalizadas em Libras capturadas em vídeo, deu-se seguimento ao processo de adaptação em que os participantes assistiram aos itens gravados pelas duplas na etapa anterior. Nessa fase, os participantes tiveram acesso à versão original do instrumento em 
Português para que pudessem comparar as afirmativas nas duas línguas. Coube a eles a tarefa de escolher uma entre as três traduções feitas na primeira etapa.

\section{Resultados}

Segundo os participantes, na maioria dos itens, as adaptações realizadas pelas três duplas foram semelhantes. Entretanto, apontaram diferenças na intensidade da expressão corporal e facial dos atores. De forma geral, eles consideraram a sinalização gravada pelos adultos surdos mais expressiva e enxuta em comparação à sinalização feita pela pessoa ouvinte. Para eles, o ouvinte teve a preocupação em adaptar de forma mais didática e detalhada, ao passo que os surdos priorizaram o uso de uma linguagem coloquial, com vocabulário de um uso mais informal.

Cada participante dessa etapa teceu alguns comentários em relação a determinados itens e sugeriu alterações como retirar repetições, acrescentar ou substituir sinais. As mudanças recomendadas foram anotadas em uma planilha. Houve divergência quanto à adaptação do enunciado da escala e em alguns itens entre os participantes, diante dessa situação, fez-se a opção por manter duas ou três possibilidades de adaptação. Depois de realizada a síntese, procedeu-se a nova gravação da adaptação da escala e a edição de um vídeo. Para essa gravação foi convidada uma surda adulta, participante da primeira etapa.

\section{Etapa III - Avaliação da Síntese por Juízes}

\section{Participantes}

Para a avaliação da síntese, as pesquisadoras, ambas ouvintes, uma psicóloga e especialista em psicometria; a outra, professora de língua portuguesa e português segunda língua para surdos, essa proficiente em português e Libras e integrada à comunidade surda, assumiram o papel de juízes.

\section{Procedimentos}

Em posse da gravação da versão síntese, além do instrumento original. As juízas verificaram a adaptação do enunciado da escala e de cada um dos itens, avaliaram se as adaptações semânticas, sintáticas e culturais dos itens mantinham equivalência com o instrumento original, assim como analisaram os itens em que houve divergência na escolha da melhor forma de traduzi-los entre os participantes da fase anterior. Após a definição da melhor versão adaptada do enunciado e de cada item do instrumento, realizou-se uma nova gravação em vídeo da escala por outro adulto surdo.

\section{Resultados}

Nessa etapa, buscou-se chegar a uma versão com a melhor forma de apresentar o instrumento tanto em vídeo quanto em papel (formato de livreto) para o participante. Em determinados itens, repetições e explicações foram consideradas desnecessárias pelos especialistas e retiradas. Em contrapartida, houve itens em que os juízes concordaram quando as afirmativas foram reforçadas com exemplos como no item "Sou capaz de realizar muitas coisas", a adaptação ficou "Sou capaz de estudar, trabalhar, criar, brincar; fazer muitas coisas". Além disso, os juízes decidiram modificar os termos "Escala Multidimensional" por "Questionário" no título do instrumento para facilitar a compreensão dos adolescentes surdos.

\section{Etapa IV-Análise Semântica da Escala em Libras pelo Grupo Focal}

\section{Participantes}

Participaram dessa etapa seis adolescentes surdos proficientes em Libras e em português escrito, com idades entre 17 e 21 anos, três do sexo feminino e três do sexo masculino. Os adolescentes eram estudantes do ensino médio de uma escola pública do Distrito Federal.

\section{Procedimentos}

Foi informado aos pais dos adolescentes com menos de 18 sobre a pesquisa e solicitada a autorização dos seus filhos para participar da pesquisa mediante a assinatura no Termo de Consentimento Livre e Esclarecido (TCLE). Antes do início da aplicação do instrumento para o grupo focal foram explicados os procedimentos e a finalidade da atividade, após foi solicitada a assinatura dos TCLEs para os adolescentes com 18 anos ou mais e do Termo de Assentimento para os menores de 18 anos. Em seguida, a pesquisadora apresentou aos participantes a primeira versão em vídeo da EMSVA em Libras e um livreto de respostas contendo os itens e a escala de respostas, conforme exemplificado na Figura 1.

"Eu gosto de ir ao shopping"

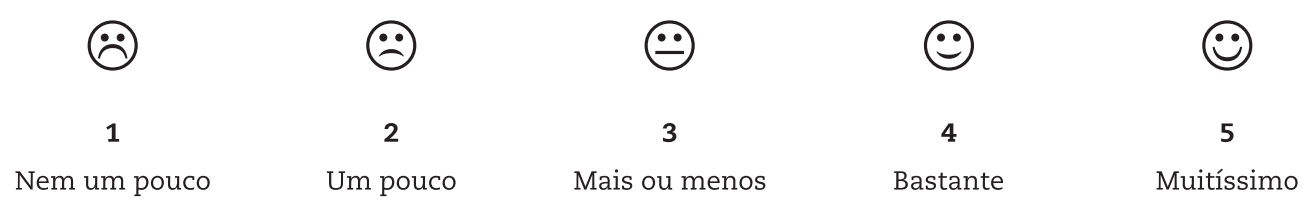

Figura 1. Exemplo de item e da escala de respostas da EMSVA adaptada em Libras 
Na projeção do vídeo, primeiro foi exibido o número do item, em um segundo momento a sinalização pelo ator e, por último, a escala de respostas. O item seguinte era apresentado após todos os participantes terem marcado a resposta no livreto. Ao término, depois de responderem a todos os itens, foi perguntado, em Libras, o que eles acharam da tarefa. As partes do enunciado ou dos itens em que foram apontadas dúvidas e dificuldades de compreensão foram reapresentadas ao grupo focal para discussão e recolhimento de sugestões para mudanças.

\section{Resultados}

Segundo Borsa, Damásio e Bandeira (2012) e Pasquali (2001), a análise semântica por um grupo focal tem por objetivo averiguar se as instruções, os itens e a escala de respostas são compreendidos com clareza pelo público-alvo a quem se destina o instrumento. Em geral, poucas dúvidas foram relatadas pelos adolescentes. Uma das mudanças sugeridas foi reforçar a marcação dos referentes "minha", "outros" e "eu".

A primeira gravação da escala adaptada em vídeo foi realizada por uma atriz adolescente surda, essa não foi bem aceita pelo grupo focal, que se demonstrou inseguro quanto às informações apresentadas, além de discordar da expressão facial e corporal da atriz com a justificativa de que a expressividade não condizia com o enunciado. Diante de tal situação, a pesquisadora interrompeu a aplicação do instrumento e retornou em outro dia com uma gravação realizada por um adulto surdo com boa expressividade. Dessa vez, o grupo focal se mostrou mais confiante, seguro, interessado e apontou a boa expressividade do ator.

\section{Etapa V - Retrotradução}

\section{Participantes}

Quatro adultos, dois surdos e dois ouvintes que não fizeram parte das fases anteriores do processo de adaptação da escala, foram organizados em duas duplas. Uma composta por um adulto surdo proficiente em Libras, com ensino médio completo, aluno de um curso profissionalizante específico para o público surdo, oralizado e com bom domínio de português escrito e um professor ouvinte bilíngue Libras/Português. A outra dupla foi formada por uma professora surda e uma professora intérprete de Libras em classe de ensino médio, ambas com formação universitária.

\section{Procedimentos}

Inicialmente a pesquisadora explicou que a proposta de trabalho consistia em fazer uma retrotradução de uma escala de satisfação com a vida, de Libras para o português. Ao concluírem a escrita dos itens, cada dupla de participantes juntos com a pesquisadora realizaram a comparação entre o português do instrumento original com o da retrotradução.

\section{Resultados}

Na maioria dos itens não houve divergências significativas, apenas no item 23 "Tenho um bom convívio com minha família", na retrotradução chegou-se a uma significação aproximada "Eu me relaciono bem com minha família”. Assim como na análise semântica, a retrotradução não implica uma tradução literal, requer a manutenção da equivalência conceitual para evitar inconsistências ou erros conceituais no instrumento adaptado quando comparado ao original. (Borsa et al., 2012; Beaton et al., 2000). Concluída a retrotradução, foi realizada a vídeo-gravação final da versão em Libras da EMSVA para adolescentes surdos por um ator surdo adulto com boa expressão facial e sólido conhecimento de Libras, não participante das etapas anteriores.

\section{Etapa VI - Análise Empírica}

\section{Participantes}

A escala adaptada e traduzida à língua de sinais foi aplicada em 50 estudantes surdos de três escolas da rede pública de ensino do Distrito Federal: uma unidade escolar especializada (UEE) e duas unidades escolares regulares (UER). Cada escola possuía características singulares. $\mathrm{Na}$ UEE $(N=28)$, as atividades escolares eram em tempo integral e as classes bilíngues, constituídas por estudantes surdos. Nessa escola, os professores regentes eram bilíngues, as aulas aconteciam sem mediação por intérpretes e a língua principal de ensino era Libras, o português escrito era ensinado como segunda língua.

Nas UER $(N=32)$, as classes bilíngues eram constituídas por estudantes ouvintes e surdos com a presença de dois professores (o regente e o intérprete de Libras). Nessas UER, o português era a principal língua de ensino, entretanto, no contra turno, os estudantes surdos frequentavam classes de Atendimento Educacional Especializado (AEE), oferecidas em salas de recursos específicas para estudantes surdos. Entretanto, as duas UER regulares tinham modalidades de ensino especializado distintas, para diferenciá-las a partir de agora serão usadas UER $1(N=16)$ e UER $2(N=6)$. A UER 1 oferecia o AEE na própria escola com professores fluentes em Libras. Na UER2, os estudantes eram encaminhados para outra instituição com proposta educacional oralista.

Entre os 50 adolescentes, $23(46 \%)$ eram do sexo masculino e 27 (54\%) do feminino, com idades entre 15 e 24 anos $(M=18,7 ; D P=2,3)$. Em relação à série: 17 (34\%) adolescentes eram estudantes do $1^{\circ}$ ano, 15 (30\%) do $2^{\circ}$ ano e $18(36 \%)$ do $3^{\circ}$ ano do ensino médio.

\section{Procedimentos}

Em cada escola, os adolescentes foram acomodados em uma sala para a projeção do vídeo em datashow. A pesquisadora explicou os objetivos da pesquisa, solicitou a 
assinatura do TCLE e do Termo de Assentimento (para os pais, o TCLE foi enviado anteriormente). Antes de projetar o vídeo da Escala Multidimensional de Satisfação de Vida para Adolescentes Surdos (EMSVA-S), também expôs a forma de aplicação do instrumento, destacou que, em caso de dúvidas, o item poderia ser reapresentado, distribuiu os livretos com os itens em português, a escala de respostas e o questionário para caracterização da amostra.

\section{Resultados}

O número de itens, a média, o desvio padrão de cada dimensão, os níveis de fidedignidade medidos pelo $\lambda^{2}$ de Guttman podem ser visualizados na Tabela 1.

A correlação item-total corrigida $\left(r_{i t}\right)$ dos itens variou de 0,15 a 0,81 . A maioria dos itens $(70 \%)$ apresentou valores de $r_{i t}$ superiores a 0,40 . Do total de 52 itens, em 18 a rit foi inferior a 0,40 , sendo a maior parte em autoeficácia; dos sete itens, cinco tiveram valores menores de 0,40 e, em não violência, de seis itens, cinco itens ficaram com valores inferiores de 0,40 .

O item 42 da subescala família "Gostaria que minha família fosse diferente" destoou dos demais itens do fator por apresentar baixa correlação, com apenas um $\mathrm{r}_{\mathrm{it}}=0,15$ e se fosse excluído, o valor da consistência interna da subescala aumentaria de 0,86 para 0,88 . Igualmente, o item 16 "Eu gostaria que meus amigos fossem diferentes" obteve apenas $r_{i t}=0,027$ e, se excluído, também elevaria o valor da consistência interna da subescala amizade, de 0,79 para 0,83 . Esses dois itens apresentaram dificuldade para adaptação para Libras, os participantes das duas primeiras etapas consideraram o significado de tais sentenças muito genérico.

Tabela 1

Média, Desvio Padrão e Consistência Interna da Escala Multidimensional de Satisfação de Vida para Adolescentes Surdos $(\mathrm{n}=50)$

\begin{tabular}{lcccc}
\hline \multicolumn{1}{c}{ Componentes } & $\mathrm{N}^{\circ}$ de itens & Média & DP & $\lambda^{2}$ de Guttman \\
\hline 1. Família & 10 & 3,81 & 0,72 & 0,86 \\
2. Self & 9 & 3,95 & 0,59 & 0,83 \\
3. Escola & 6 & 4,65 & 0,67 & 0,86 \\
4. Self & 6 & 3,88 & 0,73 & 0,80 \\
Comparado & & & & 0,52 \\
$\quad$ 5. Não violência & 6 & 2,91 & 0,54 & 0,67 \\
6. Autoeficácia & 7 & 3,70 & 0,60 & 0,79 \\
7. Amizade & 8 & 3,97 & 0,37 & 0,89 \\
Escala Total & 52 & 3,67 & & \\
\hline
\end{tabular}

Seis itens tiveram correlação item-total $\left(\mathrm{r}_{\mathrm{it}}\right)$ corrigida com valores menores que 0,30: o item 27 "Faço o que gosto de fazer" $\left(r_{i t}=0,18\right)$ e o 28 "Tenho sucesso em atividades que realizo" $\left(\mathrm{r}_{\mathrm{it}}=0,27\right)$, ambos da subescala autoeficácia. Quatro itens são da escala não violência: o 43 "Sou irritado" $\left(\mathrm{r}_{\mathrm{it}}=0,16\right)$; o 37 "Eu me sinto calmo, tranquilo" $\left(\mathrm{r}_{\mathrm{it}}=0,29\right)$; o 33 "Gosto de brigas" $\left(\mathrm{r}_{\mathrm{it}}=0,26\right)$ e o 21 "Brigar resolve problemas" $\left(r_{i t}=0,14\right)$. Como a maioria dos itens desse fator teve baixa correlação item total corrigida, optou-se por retirar essa subescala das análises posteriores. Outros seis itens apresentaram correlações consideradas baixas com os escores entre 0,30 e 0,40 (itens 2, 14,18, 19, 44, 46), entretanto, se retirados diminuem o valor da consistência interna dos fatores. Tais dificuldades também podem ter ocorrido novamente pelo tamanho da amostra.

Foram identificadas correlações significativas entre os fatores self $\mathrm{x}$ amizade $(r=0,57 ; p<0,001)$; self $\mathrm{x}$ escola $(r=0,51 ; p<0,001)$; escola $\mathrm{x}$ autoeficácia $(r=0,43 ; p<0,005)$; self $\mathrm{x}$ autoeficácia $(r=0,32 ; p<0,05)$; self $\mathrm{x}$ família $(r=0,32 ; p<0,05)$; self comparado $\mathrm{x}$ amizade $(r=0,31 ; p<0,05)$. Assim, quanto maior a satisfação com o self, maior será a satisfação com as amizades, com a escola, com a família e melhor autoeficácia. Quanto maior a satisfação com a escola melhor será a percepção de autoeficácia.

Para analisar as relações entre a percepção de satisfação de vida e as variáveis sexo, idade e tipo de escola foram utilizados testes $t$, correlação de Pearson e análises de variância. Devido às diferenças nos tamanhos da amostra nos diferentes tipos de escola, procedeu-se à análise da homogeneidade das variâncias por meio do teste de Levene para a variável tipo de escola, verificou-se que esse critério foi atendido para todas as subescalas.

Não foram encontradas diferenças significativas no que concerne à satisfação de vida entre os estudantes do sexo masculino e do sexo feminino. Segabinazi, Zortea e Giacomoni (2012) e Strelhow et al. (2010) corroboram esse resultado em que a diferença de satisfação de vida é pouco significativa entre adolescentes do sexo masculino 
e feminino. Foi encontrada correlação positiva entre idade e satisfação com a escola $(r=0,42 ; p<0,005)$. Porém, os alunos da UER1 eram mais velhos que os da UER2 e UEE. Na UER1 houve maior satisfação com a escola.

Em relação às unidades escolares, identificou-se que os estudantes da UER 1 apresentaram maior satisfação com a família $(F=4,87 ; p<0,05)$, o self $(F=3,45 ; p<0,05)$ e a autoeficácia $(F=8,08 ; p<0,001)$ que os estudantes da UEE e da UER 2. Além disso, os estudantes da UER 1 apresentaram mais satisfação com a escola $(F=18,93 ; p<0,001)$ que os estudantes da UER 2 e da UEE. Quanto à amizade e self comparado, não houve diferenças significativas na percepção de satisfação entre as três escolas pesquisadas (Tabela 2).

Tabela 2

Diferenças nas Médias das Subescalas por Unidade Escolar (UEE, UER1, UER2)

\begin{tabular}{|c|c|c|c|c|c|}
\hline Subescalas & Unidade escolar & $\mathrm{N}$ & $\mathrm{M}(\mathrm{DP})$ & $\mathrm{F}$ & $\mathrm{P} / \mathrm{H}^{2}$ \\
\hline \multirow{3}{*}{ Família } & UEE & 28 & $3,63(0,51)$ & \multirow{3}{*}{$4,87^{*}$} & \multirow{3}{*}{$\begin{array}{c}\text { UER } 1>\text { UEE } \\
d=0,87\end{array}$} \\
\hline & UER 1 & 16 & $4,18(0,75)$ & & \\
\hline & UER 2 & 6 & $4,02(0,13)$ & & \\
\hline \multirow{3}{*}{ Self } & UEE & 28 & $3,81(0,62)$ & \multirow{3}{*}{$3,45^{*}$} & \multirow{3}{*}{$\begin{array}{c}\text { UER } 1>\text { UEE } \\
d=0,87\end{array}$} \\
\hline & UER 1 & 16 & $4,26(0,43)$ & & \\
\hline & UER 2 & 6 & $3,80(0,64)$ & & \\
\hline \multirow{3}{*}{ Escola } & UEE & 28 & $3,38(0,73)$ & \multirow{3}{*}{$18,93^{* *}$} & UER 1>UEE \\
\hline & UER 1 & 16 & $4,54(0,40)$ & & $\begin{array}{c}d=2,05 \\
\text {. }\end{array}$ \\
\hline & UER 2 & 6 & $3,30(0,64)$ & & $d=2,37$ \\
\hline \multirow{3}{*}{ Autoeficácia } & UEE & 28 & $3,48(0,50)$ & \multirow{3}{*}{$8,08^{* *}$} & \multirow{3}{*}{$\begin{array}{c}\text { UER } 1>\text { UEE } \\
d=1,24\end{array}$} \\
\hline & UER 1 & 16 & $4,04(0,40)$ & & \\
\hline & UER 2 & 6 & $3,86(0,43)$ & & \\
\hline \multirow{3}{*}{ Amizade } & UEE & 28 & $3,86(0,67)$ & \multirow{3}{*}{ NS } & \multirow{3}{*}{ - } \\
\hline & UER 1 & 16 & $4,09(0,53)$ & & \\
\hline & UER 2 & 6 & $4,21(0,35)$ & & \\
\hline \multirow{3}{*}{ Self comparado } & UEE & 28 & $3,26(0,78)$ & \multirow{3}{*}{ NS } & \multirow{3}{*}{ - } \\
\hline & UER 1 & 16 & $3,14(0,69)$ & & \\
\hline & UER 2 & 6 & $3,17(0,67)$ & & \\
\hline
\end{tabular}

${ }^{1} \mathrm{UEE}=$ unidade escolar especializada; UER1=unidade escolar regular 1; UER2=unidade escolar $2 ;{ }^{2} \mathrm{P} / \mathrm{H}=p$ ost hoc de Tukey; ${ }^{*} p<0,05$ ${ }^{* *} p<0,001 ; N S=$ não significativo

\section{Discussão}

O objetivo deste estudo foi adaptar a EMSVA (Segabinazi et al., 2010) à Língua Brasileira de Sinais para adolescentes surdos na busca de tornar o instrumento acessível a esse público. A língua de sinais, como qualquer outra língua pode expressar quaisquer ideias e sentimentos, não sendo possível traduzir palavra por palavra ou frase por frase de uma língua falada, porque suas estruturas são distintas (Sacks, 1989). Desse modo, usar uma linguagem para retratar nuances de outro idioma ou cultura não é tarefa fácil. A adaptação de um instrumento de medida psicológica para a língua de sinais se constitui em uma atividade particularmente complexa devido à singularidade da língua, que ocorre na modalidade espaço-visual, diferente das línguas orais-auditivas (Samady et al., 2008; Chaveiro Duarte, Barbosa, Porto \& Fleck, 2014).
O processo de adaptação e tradução da EMSVAS seguiu etapas de análise semântica e retrotradução que garantiram um instrumento adaptado com precisão. Concorda-se com Samady et al. (2008) quanto à preocupação no desenvolvimento das primeiras etapas do método, pois estas demandam pessoas integradas à comunidade surda e bilíngues, com sólido conhecimento tanto na língua oral quanto na língua de sinais. No entanto, tais competências linguísticas ocorrem com maior frequência entre usuários das línguas com nível de escolaridade mais avançado e, portanto, podem não representar a comunidade surda como um todo. Com exceção da análise semântica pelo grupo focal e na análise empírica, a maioria dos participantes tinha ensino superior, inclusive alguns eram pós-graduados.

Com o intuito de alcançar um equilíbrio e não empregar uma linguagem inacessível ao público adolescente 
foi aplicada a escala, antes de finalizar a versão adaptada da EMSVA-S, para um grupo focal de seis adolescentes para verificar a clareza e compreensão dos itens, bem como captar sugestões que contribuíssem para melhorar o entendimento do instrumento.

Ao disponibilizar uma versão em Libras de uma escala de satisfação de vida contribuímos para a diminuição dos problemas de compreensão da leitura bastante comuns na população surda. Além disso, a adoção de recursos de imagem vem ao encontro da necessidade de comunicação dos surdos. A projeção do instrumento em vídeo privilegia o canal visual, aspecto indispensável para a interação via língua de sinais (Chaveiro et al., 2014, Pardo-Guijarro et al., 2013, Samady et al., 2008). A adaptação em Libras da EMSVAS foi aplicada para 50 adolescentes surdos demonstrando índices de fidedignidade adequados e bastante próximos aos encontrados no estudo original (Segabinazi et al., 2010).

Em relação à versão final da EMSVA-S, esta permaneceu com 52 itens, consoante à escala original, dividida em sete fatores: self, self comparado, autoeficácia, família, não violência, amizade e escola. Foram encontradas consistências internas adequadas para cinco das sete subescalas, assim como para a escala total. As subescalas autoeficácia e não violência apresentaram baixos índices de fidedignidade, semelhantes ao estudo original da escala, pois as duas subescalas não violência $(0,54)$ e autoeficácia $(0,67)$ também apresentaram coeficientes de CI baixos. Esses resultados foram explicados pelo número de itens das subescalas, uma vez que elas são compostas com o menor número de itens, 6 e 7 , respectivamente (Segabinazi et al., 2010). Considera-se, no entanto, a necessidade de revisão das duas subescalas tanto no instrumento original quanto em sua versão em Libras.

Considera-se ainda que a baixa consistência interna na subescala não violência pode ter ocorrido devido ao formato dos itens que se apresentam em sentido negativo, como evidenciado pelas baixas correlações item-total nos itens que estão no sentido de violência. Assim, supõe-se que, é mais fácil o adolescente afirmar "bastante" para uma característica bem aceita pela sociedade ("Eu me sinto calmo") a afirmar "bastante" para aspectos da personalidade considerados inadequados pela sociedade ("Sou irritado").

Ao associar ambiente educacional e satisfação de vida, na literatura encontra-se melhores índices de satisfação para os adolescentes que frequentavam a escola específica para surdos (Al-shammari1, et al., 2014, Hintermair, 2008). A presente pesquisa contraria esses estudos ao apresentar resultados mais expressivos de satisfação de vida para os adolescentes estudantes da UER $1 \mathrm{em}$ que alunos surdos e ouvintes compartilhavam o mesmo espaço escolar. Por outro lado, ao comparar a UEE e a UER2, os resultados não mostraram diferenças significativas quanto aos níveis de satisfação de vida.
Ante o exposto, pode-se atribuir a maior satisfação de vida dos adolescentes da UER 1 devido tanto às características físicas da escola quanto pela associação entre frequentar as classes regulares com a mediação das atividades por um intérprete educacional e, no contra turno, ter disponível um AEE com professores proficientes em Libras e em português. Nessa escola, os surdos convivem no espaço escolar com seus pares ouvintes, mas também têm acesso a um ambiente em que se encontram apenas com seus pares surdos e professores bilíngues que disponibilizam atividades suplementares às desenvolvidas na sala de aula comum. Essa forma de funcionamento escolar é mais coerente com as propostas características da educação inclusiva (Bissoto, 2013, Mantoan, 2012), diferentemente dos atendimentos feitos nas UEE e UER2, mais distantes do que propõe a inclusão. Na UEE, a escola atende prioritariamente pessoas surdas e, na UER2, a linguagem oral é privilegiada no AEE.

Possibilitar aos surdos terem acesso a instrumentos de medida psicológica em Libras vem ao encontro dos anseios da população surda que luta pelo reconhecimento de sua singularidade linguística e cultural. Além disso, pode constituir em uma oportunidade a mais de preencher a lacuna no conhecimento sobre o que pensam, sentem e avaliam sobre si mesmos os adolescentes surdos acerca de sua satisfação de vida. Outros aspectos somam-se aos já citados: a contribuição que um instrumento adaptado em Libras oferece para a eficácia na sua aplicação, a maior confiabilidade dos resultados, uma vez que muitos surdos têm dificuldades de ler e compreender a língua oral (Samadyet al. 2008, Pardo-Guijarro et al.,2013; Chaveiro et al., 2013). Segundo Mantoan (2012), esse movimento pela inclusão implica uma mudança de postura, pois rompe com barreiras físicas, atitudinais, comunicacionais que impossibilitam alguns grupos com características diferenciadas de participar, compartilhar com as demais pessoas da vida social, escolar, familiar, laboral, como cidadãos com direitos e de deveres comuns a todos.

No entanto, estudos de validade e fidedignidade mais robustos precisam ser desenvolvidos para que a EMSVA-S se torne um instrumento útil para adolescentes surdos. Espera-se, incentivar novas pesquisas a fim de possibilitar a identificação dos adolescentes surdos com problemas de saúde relacionados ao bem-estar subjetivo e, a partir disso, despertar o interesse por ações em diversas áreas da sociedade que visem uma vida melhor e a inserção na sociedade com maior equidade para todos (Bissoto, 2013; Pardo- Guijarro et al., 2013).

Uma das limitações desta pesquisa foi a impossibilidade do uso da EMSVA-S na forma de autoaplicação. $\mathrm{O}$ instrumento autoadministrado, via computador, permitiria aos participantes respondê-lo na tela com maior autonomia ao interagir com o instrumento, seja na visualização das orientações de como responder a escala ou na apresentação de cada item. 
A comunicação em língua de sinais é um forte traço cultural e de pertencimento na comunidade surda (Chaveiro et al.,2014), logo, espera-se contribuir para pesquisas futuras no tocante à construção e adaptação de instrumentos alicerçados na Psicologia Positiva para os surdos. Aliás, é inegável que, na aurora do século
XXI, ante inúmeras e rápidas transformações sociais, a Psicologia se renove e amplie sua visão voltando seus estudos também para aspectos positivos da vida, como a compreensão das forças e virtudes de todas as pessoas (Veenhoven, 1994; Paludo \& Koller, 2007; Passareli \& Silva, 2007).

\section{Referências}

Al-shammari, M., Ashankyty, A., Al-Mowina1, N., Al-Mutairy, N., Al-shammari, L., Al-qrnas, A., \& Amin, S. (2014). Social-Emotional Perceptions of Deaf Students in Hail, Saudi Arabia. American Journal of Educational Research, 2(5), 304-315. doi: 10.12691/education-2-5-11

Beaton, D. E., Bombardier, C., Guillemin, F., \& Ferraz, M. B. (2000). Guidelines for the process of cross-cultural adaptation of self-report measures. Spine, 25(24), 3186-3191. doi: 10.1097/00007632-200012150-00014

Bissoto, M. L. (2013). Educação inclusiva e exclusão social. Revista Educação Especial, 26(45), 91-108. doi: 10.5902/1984686X5434

Borsa, J. C., Damásio, B. F., \& Bandeira, D. (2012). Adaptação e validação de instrumentos psicológicos entre culturas: algumas considerações. Paidéia, 22(53), 423-432. doi: 10.1590/S0103-863X2012000300014

Brito, L. F. (1995). Por uma gramática de Língua de Sinais. Rio de Janeiro: Tempo Brasileiro.

Chaveiro, N., Duarte, S. B. R., Barbosa, M. A., Porto, C. C., \& Fleck, A. M. P. (2014). Qualidade de vida dos surdos que se comunicam pela língua de sinais: revisão integrativa. Revista Interface: Comunicação, Saúde e Educação, 18(48), 101-114. doi: 10.1590/1807-57622014.0510

Chaveiro, N., Duarte, S. B. R., Barbosa, M. A., Porto, C. C., \& Fleck, A. M. P. (2013). Instrumentos em Língua Brasileira de Sinais para avaliação da qualidade de vida da população surda. Revista de Saúde Pública, 47(3), 616-23. doi: 10.1590/S0034-8910.2013047004136

Diener, E., Suh, E., Lucas, R., \& Smith, H. (1999). Subjective well-being: Three decades of progress. Psychological Bulletin,125(2), $276-302$. doi: 10.1037/0033-2909.125.2.276

Galinha, I. C., \& Ribeiro, J. L. (2005). História e evolução do conceito de bem-estar subjectivo. Psicologia, Saúde E Doenças, 6(2), $203-214$. Recuperado de https://www.redalyc.org/articulo.oa?id =36260208\&idp=1\&cid=3412262

Hintermair, M. (2008). Self-esteem and Satisfaction With Life of Deaf and Hard-of-Hearing People-A Resource-Oriented Approach to Identity Work. Journal of studies and Deaf Education, 13(2), 278-300. doi: 10.1093/deafed/enm054

Lewis, A. D., Huebner, E. S., Malone, P. S., \& Valois, R. F. (2011). Life satisfaction and student engagement in adolescents. Journal of Youth and Adolescence; 40(3), 249-262. doi: 10.1007/s10964-010-9517-6

Mantoan, M. T. E. (2012). Escolas dos diferentes ou escolas das diferenças? ComCiência, 135, 1-3. Recuperado de http://federacaodown.org. br/wp-content/uploads/2018/11/Escola-dos-diferentes-ou-escolas-das-diferen\%C3\%A7as_Maria-Teresa-Mantoan.pdf

Myers, D., \& Diener, E. (1995). Who is happy? Psychological Science, 6(1), 10-19. Recuperado de http://www.psychology.hku.hk/ftbcstudies/ refbase/docs/myers/1995/62_Myers+Diener1995.pdf

Paludo, S. S., \& Koller, S. H. (2007). Positive Psychology: A new approach to old questions. Paidéia, 17(36), 9-20. doi: 10.1590/S0103$863 \mathrm{X} 2007000100002$

Pardo-Guijarro, M. J., Woll, B., Moya-Martínez, P., Martínez-Andrés, M., Cortés-Ramírez, E. E., \& Martínez-Vizcaíno, V. (2013). Validity and reliability of the Spanish sign language version of the KIDSCREEN-27 health-related quality of life questionnaire for use in deaf children and adolescents. Gaceta Sanitaria; 27(4), 318-324. doi: 10.1016/j.gaceta.2012.11.003

Pasquali, L. (2001). Técnicas de Exame Psicológico - TEP. Manual de fundamentos das técnicas psicológicas. São Paulo: Casa do Psicólogo.

Passareli, P. M., \& Silva, J. A. (2007). Psicologia Positiva e o estudo do bem-estar subjetivo. Estudos de Psicologia, 24(4), 513-517. Recuperado de http://www.scielo.br/pdf/estpsi/v24n4/v24n4a10.pdf

Sacks, O. (1998). Vendo vozes: Uma viagem ao mundo dos surdos. (L. T. Motta, tradução do original "Seeing voices: a journey into the world of the deaf Bibliografia”.). São Paulo: Companhia das Letras.

Samady, W., Sadler, G. R., Nakaji, M., \& Malcarne, V. L. (2008). Translation of the Multidimensional Health Locus of Control scales for users of American Sign Language. Public Health Nursing, 25(5), 480-489. doi: 10.1111/j.1525-1446.2008.00732.x

Segabinazi, J. D., Giacomoni, C. H., Dias, A. C. G, Teixeira, M. A. P., \& Moraes, D. A. O. (2010). Desenvolvimento e Validação Preliminar de uma Escala Multidimensional de Satisfação de Vida para Adolescentes. Psicologia: Teoria e Pesquisa, 26(4), 653-659. doi: 10.1590/ S0102-37722010000400009

Segabinazi, J. D., Zortea, M. C., \& Giacomoni, C. H. (2012). Avaliação de Bem-estar Subjetivo em Adolescentes. Em C. S. Hutz (Eds.), Avaliação em Psicologia Positiva (pp. 69 - 84). Porto Alegre: Artmed.

Seligman, M. E. P., \& Csikszentmihalyi, M. (2000). Positive psychology: An introduction. American Psychologist, 55(1), 5-14. doi: 10.1037/0003066X.55.1.5

Silva, D. G. D., Giordani, J. P., \& Dell'Aglio, D. D. (2017). Relações entre satisfação com a vida, com a família e com as amizades e religiosidade na adolescência. Estudos Interdisciplinares em Psicologia, 8(1), 38-54. Recuperado de http://pepsic.bvsalud.org/pdf/eip/v8n1/ a04.pdf

Skliar, C. (2013). A localização política da educação bilíngue para surdos. Em C. Skliar (Org.), Atualidacde da Educação Bilíngue para Surdos: Interfaces entre Pedagogia e Linguística (pp. 7-14). Porto Alegre, RS: Mediação.

Strelhow, M. R. W., Bueno, C. O., \& Câmara, S. G. (2010). Percepção de saúde e satisfação com a vida em adolescentes: diferença entre os gêneros. Revista Psicologia e Saúde, 2(2), 42-49. Recuperado de http://www.gpec.ucdb.br/pssa/index.php/pssa/article/viewFile/62/99 
Veenhoven, R. (1994). El estudio de la satisfacción con la vida. Intervención Psicosocial, 3(9), 87-116. Recuperado de https://personal.eur.nl/ veenhoven/Pub1990s/94d-fulls.pdf

\section{Sobre os autores}

Rosângela Prescendo Tonin é graduada em Letras e mestre em Psicologia pela Universidade Católica de Brasília. Atualmente é professora da Secretaria de Educação do Distrito Federal de Língua Portuguesa, Língua Portuguesa para Surdos e Informática na Educação Infantil.

Cláudia Cristina Fukuda é psicóloga, doutora em Psicologia pela Universidade de Brasília. Atualmente é professora do Programa Stricto Sensu em Psicologia da Universidade Católica de Brasília. 